\title{
OJS

\section{OLHARES GEOGRÁFICOS SOBRE A CIDADE: PROPOSTAS METODOLÓGICAS NO ENSINO DE GEOGRAFIA}

\author{
Gabriel de Miranda Soares Silva ${ }^{1}$, Meire Rose dos Anjos Oliveira² \\ 'Discente de mestrado no Programa de Pós-graduação em Geografia da Universidade Federal do Mato Grosso (UFMT). \\ E-mail: soares.ufmt@gmail.com - ORCID iD: http://orcid.org/0000-0002-4651-3640; \\ 2Professora do Departamento de Geografia da Universidade Federal do Mato Grosso (UFMT). E-mail: \\ meirerosegeo@yahoo.com.br.ORCID iD: http://orcid.org/0000-0002-6783-9420.
}

Artigo recebido em 30/04/2020 e aceito em 15/06/2020

\begin{abstract}
RESUMO
Neste artigo propomos discutir a cidade como condutora no processo de ensino-aprendizagem de Geografia, partindo da percepção dos agentes urbanos, buscando um olhar geográfico dos alunos do ensino médio sobre cidade e seu cotidiano. Apresentamos diferentes propostas metodológicas para o ensino de Geografia urbana, dentre estas atividades destacamos: a atividade e a aula de campo, a realização de registros fotográficos e por último a confecção e aplicação de um jogo de tabuleiro. Desta forma, os alunos puderam compreender a cidade onde vivem, o nome dos agentes históricos e o processo de formação das características socioespaciais da cidade de Várzea Grande - MT. Consideramos que as atividades balizam a proposta de uma educação sócioconstrutivista pautada nos saberes dos alunos aliados aos conceitos da Geografia, dando significado a Geografia na/da escola.

Palavras-chave: Aula de Campo. Fotografia. Jogo de Tabuleiro. Várzea Grande - MT.
\end{abstract}

\section{GEOGRAPHIC VIEWS OF THE CITY: METHODOLOGICAL PROPOSALS IN TEACHING GEOGRAPHY}

\begin{abstract}
In this article we propose to discuss the city as a guide in Geography teaching-learning process, starting from the perception of urban agents, looking for a geographical sight from high school students about the city and their daily lives. We present different methodological proposals for the teaching of Urban Geography, among these activities we highlight: the field activity and class, the making of photographic records and finally, the making and application of a board game. Thus, students were able to understand the city where they live, the name of the historical agents and the process of formation of the socio-spatial characteristics of the city of Várzea Grande, MT. We consider that the activities beacon the proposal for a socio-constructivist education based on the students' knowledge combined with the concepts of Geography, giving meaning to Geography at and from school.
\end{abstract}

Keywords: Field Class. Photography. Board Game. Várzea Grande, MT. 


\title{
VISIONES GEOGRÁFICAS DE LA CIUDAD: PROPUESTAS METODOLÓGICAS EN LA ENSEÑANZA DE LA GEOGRAFÍA
}

\begin{abstract}
RESUMO
En este artículo nos proponemos discutir la ciudad como motor del proceso de enseñanza-aprendizaje de la Geografía, a partir de la percepción de los agentes urbanos, buscando una visión geográfica de los estudiantes de secundaria sobre la ciudad y su vida cotidiana. Presentamos diferentes propuestas metodológicas para la enseñanza de la Geografía urbana, estas actividades destacan: la actividad y la clase de campo, la realización de registros fotográficos y finalmente la realización y aplicación de un juego de fichas. De esta manera, los estudiantes pudieron comprender la ciudad donde viven, el nombre de los agentes históricos y el proceso de formación de las características socioespaciales de la ciudad de Várzea Grande - MT. Considerar que las actividades orientan la propuesta de una educación socioconstructivista basada en el conocimiento de los estudiantes combinado con los conceptos de Geografía, dando sentido a la Geografía en / en la escuela.
\end{abstract}

Palavras clave: Clase de campo. Fotografía. Juego de mesa. Várzea Grande - MT.

\section{INTRODUÇÃO}

Compreender a cidade, seus agentes e sujeitos é um dos objetivos da Geografia enquanto disciplina escolar. Se as cidades chamam a atenção de engenheiros, arquitetos, sanitaristas de diversas maneiras, na educação também deveria ser um elemento de grande importância. E ela é tema de vários estudos na área de educação, inclusive da Geografia Escolar, pois, os jovens estudantes se deparam com os temas referentes à Geografia urbana ao longo dos vários anos da educação básica. Consideramos que o ensino ocorre a partir do processo de ensino e aprendizagem e, neste processo há dois sujeitos - os alunos e os professores. Aos alunos cabe interagir com o cotidiano do processo com suas experiências e novos questionamentos; aos professores cabe empregar as diferentes metodologias para apresentar a cidade e suas distintas nuances para os alunos.

Para Lana Cavalcanti (2008, p. 63) “[...] existe uma forte conexão entre a produção desse lugar a cultura das pessoas que nele vivem", ou seja, a cidade é um lugar de formação. Aprender Geografia através da cidade poderá levar os alunos a constituírem modos de vista, formas de pensar o espaço utilizado e construído cotidianamente.

Apresentaremos neste artigo uma síntese histórica do processo de urbanização do município de Várzea Grande - MT, compreendendo a formação da cidade e dos diferentes espaços urbanos. Isto para desenvolver uma relação entre o conhecimento do urbano e o escolar como base do saber de sujeitos plenos que saibam utilizar o que é aprendido na escola para a interpretação e ressignificação de seu cotidiano. 
A pesquisa foi desenvolvida na Escola Estadual Professora Elmaz Gattas Monteiro, que se localiza na cidade de Várzea Grande - MT, onde realizamos as propostas metodológicas: aula e trabalho de campo, atividades de fotografia e aplicação do jogo de tabuleiro.

Dividimos esta pesquisa em diferentes momentos, primeiro com a aproximação da escola para a realização das demais atividades. O segundo momento referiu-se a realização da aula e trabalho de campo e, por fim, a confecção e aplicação de um jogo de tabuleiro. Desta forma o trabalho permitiu a compreensão de que os alunos aprendem e relacionam os conceitos da Geografia experimentando os diferentes métodos de maneira lúdica.

\section{UM OLHAR SOBRE A CIDADE DE VÁRZEA GRANDE - MT}

O município de Várzea Grande está localizado na região Centro-Sul do estado de Mato Grosso e compõe a Região Metropolitana do Vale do Rio Cuiabá, é o terceiro maior município em índices econômicos e o segundo em dados populacionais, ficando atrás somente da capital do estado Cuiabá.

Várzea Grande é fundada em meados do século XIX, durante o conflito travado entre o Paraguai e a Tríplice Aliança formada pelo Brasil, Argentina e Uruguai. Com a prisão de paraguaios na guerra foi necessário a formação de um acampamento militar na margem direita do rio Cuiabá, neste local anos mais tarde se constituiria o município de Várzea Grande. O que é possível perceber na leitura de Freire (1997, p. 56, grifo do autor), o autor destaca que:

[...] A Guerra do Paraguai estende seus reflexos à fisionomia da cidade. No Porto Geral, às margens do Cuiabá, implanta-se o acampamento militar Couto Magalhães, dando origem à formação de um bairro popular, que irá atingir grande densidade populacional na primeira metade do século XX. Em frente ao Porto, na margem direita do Cuiabá, forma-se um novo núcleo urbano, a partir de acampamento e prisão militar. Esse núcleo mais tarde dará origem à cidade de Várzea Grande.

Monteiro (1989) relata que havia casas com tijolos de adobe (barro), alguns lavradores espalhados palas orlas e capões nas encostas do rio Cuiabá, onde se desenvolviam as principais atividades econômicas da população local. De acordo com os escritos de Ferreira (2008, p. 230), “[...] a denominação Várzea Grande se deve à extensa planície, na qual o núcleo se originou e se desenvolveu, abrangendo enormes várzeas”. Em meados do século XVI a dinâmica do rio Cuiabá permitia que no período de cheia a água do rio extrapolasse as margens (talvegue), esta se acumulava em grandes várzeas, de onde se origina o nome do município. 
Aproximadamente 25 anos após a fundação do acampamento militar, era construída uma pequena igreja - de Nossa Senhora da Guia - como aponta a figura 01. No entorno dessa igreja, a população passou a estabelecer moradias. Na leitura de Marx (1991, p.43) "[...] a capela acolhe moradores em pequenas porções [...]”, ou seja, a igreja assume papel importante na organização urbana e desta forma “[...] torna-se instrumento de urbanização e cria uma nova paisagem [...]".

Figura 01: Igreja de Nossa Senhora da Guia no ano de 1892

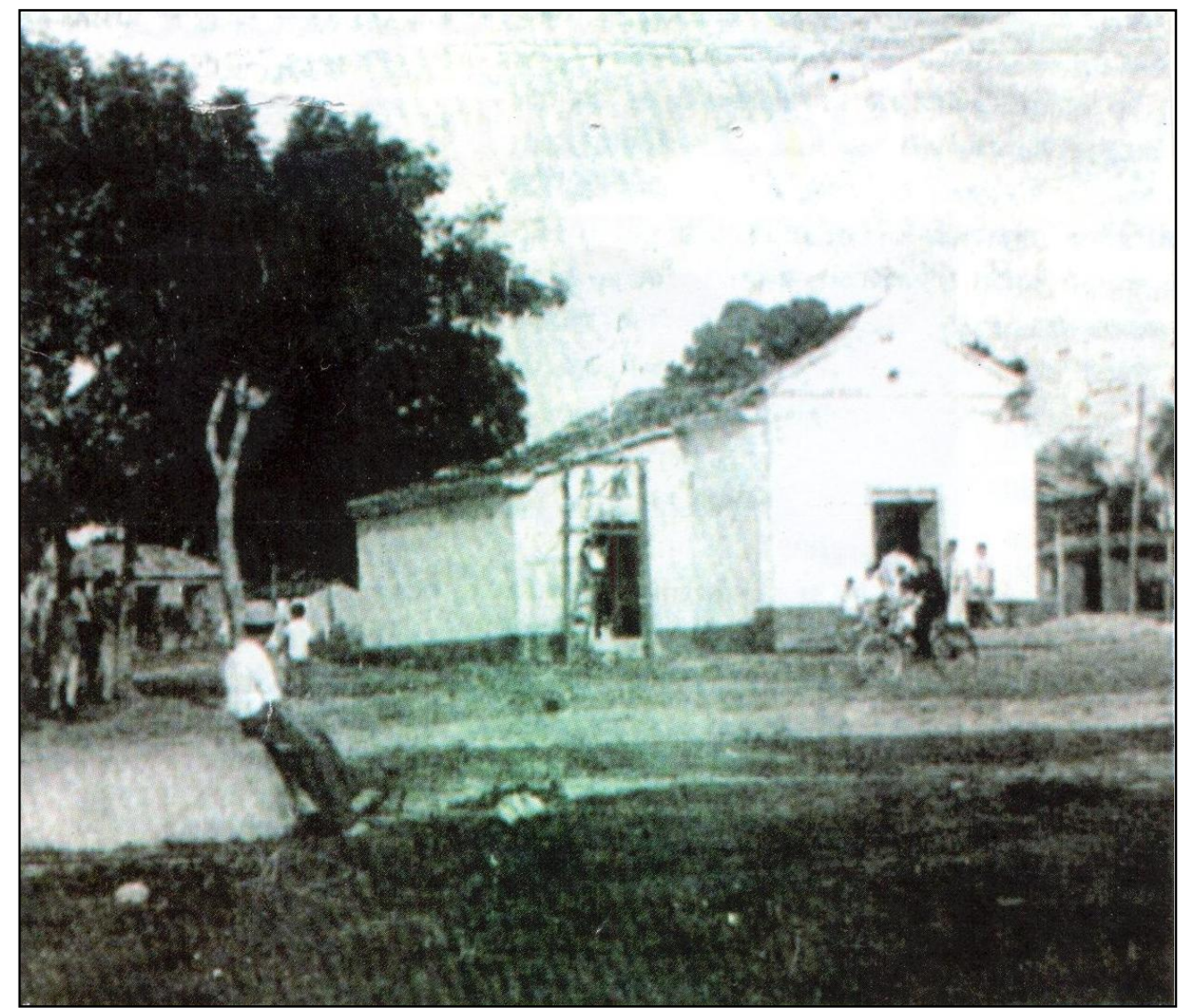

Fonte: Acervo Fundação Júlio Campos (2013).

O processo de construção da Igreja Nossa Senhora da Guia é destaque na leitura de Romancini e Silva (2016, p. 146), cuja construção se deu “[...] durante os anos de 1890 e 1892 com a ajuda da população que morava em Várzea Grande, os moradores da Guarita, Passagem da Conceição, Manga e do Porto. No ano de 1892 terminou a construção da igreja e foi marcada a primeira missa $[\ldots] "$ ".

Várzea Grande, como aponta Ferreira (2014) sempre mostrou vocação para ser cidade de destaque no contexto regional, o autor descreve que, nos primeiros moradores já se enxergava uma autoconfiança em relação ao futuro da pequena vila que se transformaria em cidade. 
A partir do momento da criação do acampamento militar é formada uma vila, que posteriormente é elevada à categoria de distrito subordinado ao município de Cuiabá, até que no ano de 1948, sob a Lei Estadual de no 126/1948, foi emancipado se desmembrando da capital do estado, Cuiabá.

No decorrer dos anos a população várzea-grandense passou a ocupar as áreas não edificadas que havia na cidade, houve incentivo por programas habitacionais desenvolvidos pelo poder público e pelo setor privado, o que alavancou desde a década de 1970 a expansão horizontal da cidade e consolidou o processo de urbanização iniciado no século XIX (BRASIL, 2018).

A ocupação urbana entre os anos de 1960-1970 apresentou características similares às que ocorreram em Cuiabá, com destaque ao processo de industrialização que tomou força com a criação do distrito industrial, como coloca Silva (2014). A cidade passou a ser conhecida por "Várzea Grande Cidade Industrial".

Como grande parte das cidades brasileiras Várzea Grande com o passar dos anos acumulou problemas urbanos e, levando isso em consideração, no ano de 2007 a prefeitura municipal regulamenta o plano diretor municipal sob a Lei Complementar 3.112, Com esse aparato legislativo, o poder público municipal procurou sanar alguns dos vários problemas de estruturação urbana no município. Já em 2012, com a Lei Complementar 3.727/2012 que dispõe do zoneamento urbano e de uso e ocupação do solo, foram regulamentadas as atividades exercidas no solo urbano.

\section{OLHARES SOBRE AS PRÁTICAS METODOLÓGICAS NO ENSINO DE GEOGRAFIA URBANA}

O desenvolvimento prático desta atividade com os estudantes ocorreu, em um primeiro momento, por meio da explanação do conteúdo referente a organização/reorganização espacial urbana de Várzea Grande - MT. O domínio deste conteúdo se dá em função da realização da disciplina "Projetos Educativos em Geografia Humana". Essa disciplina compõe a grade curricular do curso de Licenciatura em Geografia da Universidade Federal de Mato Grosso a qual os autores tiveram a oportunidade de analisar e interpretar os principais atores, processos e impactos resultantes da aglomeração humana neste recorte espacial.

Nesta disciplina os acadêmicos procuram desenvolver projetos que auxiliam os professores da educação básica no cotidiano escolar. Escolhemos a Escola Elmaz Gattas Monteiro para o desenvolvimento das atividades. Enfatiza-se que é uma instituição pública, localizada na cidade de 
Várzea Grande, no bairro Centro Sul próximo ao Aeroporto e ao Várzea Grande Shopping como aponta a figura 03. Apesar de se tratar de uma escola da Região Central, em sua grande maioria, os estudantes são oriundos de bairros periféricos da cidade, isto acarreta a realidade vivenciada pelos alunos e nas dificuldades encontradas pela coordenação pedagógica, diante dos índices de desempenho escolar.

Figura 03: Localização da Escola Estadual Elmaz Gattas Monteiro

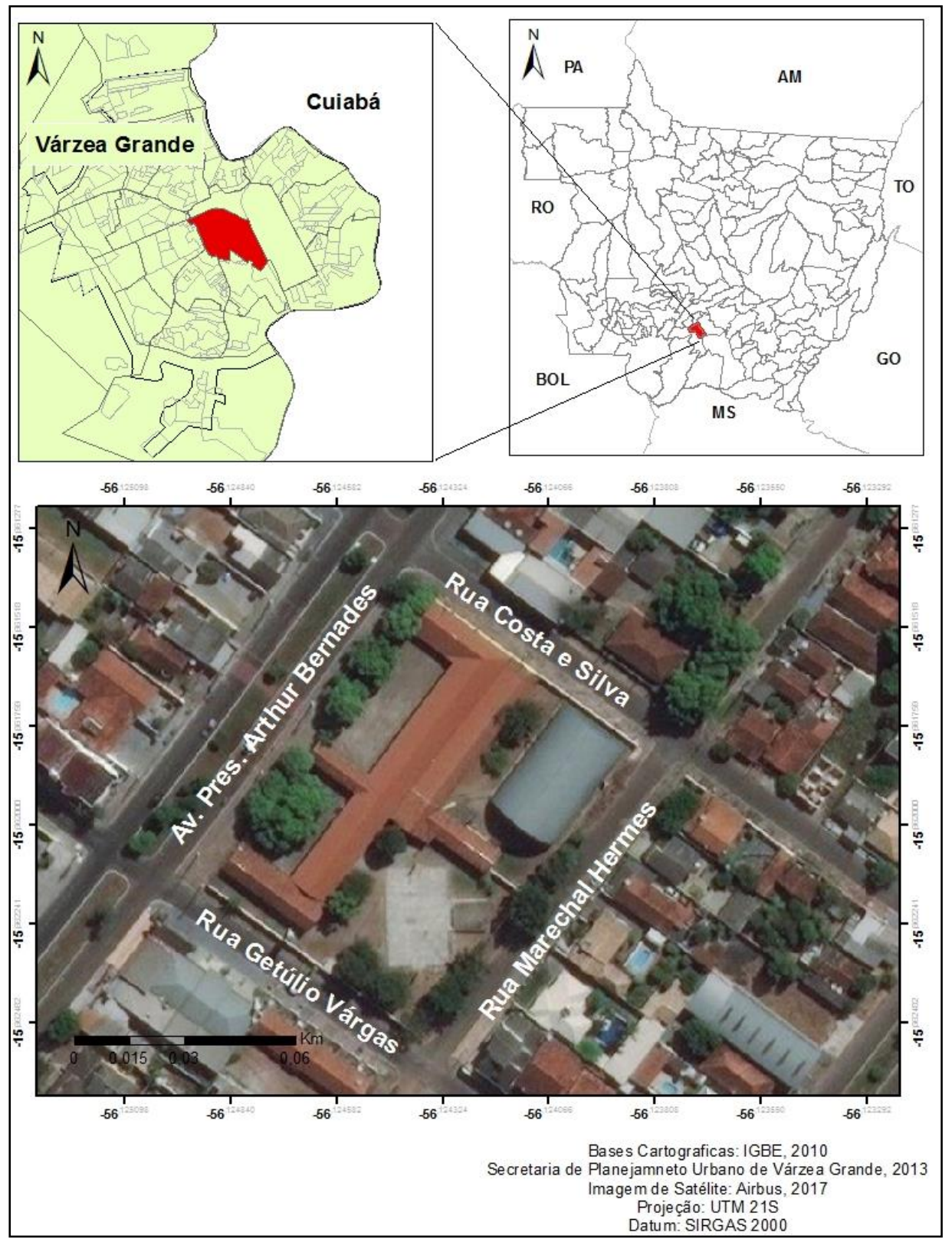

Fonte: Gabriel M. S. Silva (2019).

A proposta metodológica delineada se divide em diferentes momentos, no primeiro momento buscou-se uma aproximação com a realidade vivida dos discentes do $2^{\circ}$ ano do Ensino Médio, já que o conteúdo proposto se apresenta neste ano escolar, apresentamos a síntese histórica 
do município de Várzea Grande e demais conceitos da Geografia Urbana como êxodo rural, segregação socioespacial e expansão urbana.

Em seguida foi proposta uma atividade de campo na área central da cidade com um roteiro previamente estipulado, onde os alunos tiveram a oportunidade de realizar registros fotográficos e registrar o seu olhar sobre Várzea Grande. As fotos foram selecionadas e compuseram um painel fotográfico que foi exposto na escola e, por fim, foi produzido um jogo de tabuleiro onde os discentes puderam se deparar com vários dos conceitos apresentados em sala de aula e durante a atividade de campo.

As atividades foram propostas com base na construção do conceito de educação socioconstrutivista, que é amplamente analisado por Cavalcanti (1998, p.77) que “ [...] destaca a importância dos conhecimentos científicos como referência para a compreensão da realidade e o entendimento de que os processos de conhecimento é um processo ativo do aluno, com suas peculiaridades e seus conhecimentos anteriores".

A autora ainda destaca que todos os conteúdos referentes ao ensino de Geografia devem ser vistos como instrumento, contribuindo com as práticas sociais e socioespaciais desenvolvidas pelos alunos ao longo do ensino fundamental e médio (CAVALCANTI, 1998).

Foi dito anteriormente que a escola está localizada na região central de Várzea Grande, na turma onde se desenvolveu as atividades existem alunos de vários bairros da cidade, o que proporcionou a construção de alguns conceitos, como de segregação socioespacial, expansão e mobilidade urbana o que favorece a construção do saber geográfico.

A construção do saber geográfico escolar é de suma importância já que a Geografia se revela como disciplina que possui significativa contribuição na formação de cidadãos. A educação geográfica descrita por alguns autores deve contribuir para que estas competências e habilidades da educação geográfica, seja desenvolvida, como destacam Castellar e Vilhena (2010, p. 121), onde o

[...] método de análise da realidade vivida. Nessa perspectiva, torna-se possível aos alunos sair do estágio de impressionismo de aparências. Aprofundando as decodificações sobre a cidade, busca-se entendê-la como uma nova organização do território, como articulação dos espaços descontínuos e fragmentados e como parte da experiência real de vida dos alunos. Daí não se retomarem as temáticas escolares em relação ao que está próximo ou distante, o entorno ou as delimitações tradicionais da cidade em tipos de bairros, por exemplo. Ainda que tais conteúdos sejam "mais fáceis" de entender, pela simplificação do objeto que se busca conhecer, sua relevância é diminuída - e, por vezes, deletéria - em um projeto educativo que visa possibilitar a compreensão efetiva e a apropriação do conhecimento transformador sobre a cidade como método por excelência para uma real compreensão geográfica de lugares e espaços. 
A fim de chegar à compreensão de parte da região central de Várzea Grande é que as atividades tiveram por objetivo propor uma análise sobre o cotidiano dos alunos, que vivenciam a cidade de diferentes formas. A análise está sobre o espaço urbano, que partiu da perspectiva socioconstrutivista onde os alunos da escola indicarão a sua visão sobre a cidade. Evidenciamos que estudar a cidade não corresponde apenas em observar paisagens e seus problemas, como a verticalização, identificar as áreas centrais e periféricas, as dificuldades de abrangência e locomoção, existem outras perspectivas e modos de observar, e tecer uma síntese sobre as práticas socioespaciais que moldam o espaço urbano.

Assim, os alunos precisam compreender que existem outras dimensões para compreender o espaço urbano,

[...] que há várias cidades que possuem arranjos espaciais diversos, gestados em função não só do meio físico, mas do planejamento urbano e sua sobre determinação econômica. Fenômenos a expansão das áreas urbanas - e mesmos subterrâneos (estacionamentos, fiação de luz e telefonia, metrô) - devem ser articuladas com o fenômeno produtivos e/ ou culturais que têm lugar no urbano (CASTELLAR; VILHENA, 2010, p. 121-122).

Com base nos saberes adquiridos na escola os alunos aprimoraram seus conhecimentos sobre a cidade e o urbano, buscando tecer um olhar geográfico sobre a cidade. Assim, buscamos não priorizar os conteúdos tradicionais, e sim os vivenciados pelos alunos, aliando-os com as práticas espaciais do cotidiano, e uma reflexão acerca deste espaço (urbano) vivido (KAERCHER, 2006).

Desta forma, as propostas metodológicas apresentadas a seguir levam em consideração estas concepções metodológicas, já que os discentes vivenciam a cidade no seu cotidiano, os saberes já adquiridos por eles serão levados em consideração, assim balizando a construção do saber geográfico.

\section{Aula e trabalho de campo}

Para a Geografia as atividades de trabalho de campo são de extrema importância, já que dentre os conteúdos analisados dentro de sala de aula, o professor deve fazer com que os alunos viagem sobre os conceitos, por meio não apenas dos conteúdos, mas também com auxílio de fotos, vídeos e outros materiais pedagógicos. Ou seja, quando é possível realizar uma saída para trabalho de campo, os conteúdos ganham vida e a compreensão da turma se torna de certa forma mais fácil.

Nos escritos de Oliveira (2010, p. 153), o autor diferencia os termos "trabalho de campo e aula de campo", o primeiro é o processo de pensar, agir, registrar, coletar informações, já o segundo 
o movimento de sair do padrão clássico de ensino e procurar outros espaços para uma aula. No entendimento de Castellar e Vilhena (2017), o trabalho de campo é

[...] um monumento especial para o aluno na medida que o professor pode articular os conhecimentos teóricos do conteúdo desenvolvidos em sala de aula com a observação dos fenômenos e objetos do lugar em questão. Assim o trabalho de campo não será uma mera observação, mas um aprofundamento dos conceitos científicos. Por isso, é importante que o professor, antes de levar os alunos, faça um reconhecimento das potencialidades deles e elabore um roteiro de estudo. (CASTELLAR, VILHENA, 2010. p. 7).

A proposta em questão evidencia a oportunidade de vivenciar momentos em que os alunos possam observar toda a dinâmica de transformação do espaço geográfico, e, também, refletir sobre as implicações dessas transformações. Theves e Kaercher (2017, p. 286) discorrem que,

A saída de campo e as atividades desenvolvidas a partir dele deram sentido as informações obtidas, pois estas foram contextualizadas em relação aos estudos que já estavam sendo realizados e novos saberes foram se constituindo através do diálogo e da reflexão medida pela interação entre alunos, professores e mundo (THEVES E KAERCHER, 2017, p. 286).

Ressaltamos que o trabalho de campo se destaca como uma das principais ferramentas metodológicas no que tange o processo de ensino e aprendizagem de Geografia, em vários níveis de ensino. Sob este contexto Cantóia (2014, p. 273) ainda retrata que é

papel do professor de Geografia inserir debates em sala que retratem a realidade vivida pelos alunos, sejam eles da educação básica, seja de cursos de graduação do ensino superior. O trabalho de campo, como instrumento pedagógico e didático que visa ter um apanhado da realidade, é uma das formas de suscitar o debate e agregar diferentes formas de ações com os alunos.

Sendo assim, o trabalho de campo deve ser planejado e seus objetivos definidos, já que ao sair do ambiente escolar imprevistos poderão acontecer (Pontuschka, et al, 2007). Dentre os objetivos a serem alcançados destacamos a observação empírica das transformações socioespaciais, que aconteceram na área central de Várzea Grande.

A atividade de campo aconteceu no dia 02 de julho de 2018, no período vespertino com o roteiro que iniciou na praça Aquidabam na avenida Couto Magalhães (ponto A), saindo da praça nos dirigimos até a igreja Nossa Senhora do Carmo (ponto B), e seguimos em direção a Escola Pedro Gardés (ponto C), depois até a Igreja de Nossa Senhora da Guia (ponto D), indo em direção ao terminal de integração André Maggi (ponto E), último ponto do roteiro, como aponta a figura 04. 
Figura 04: Roteiro do Trabalho de Campo

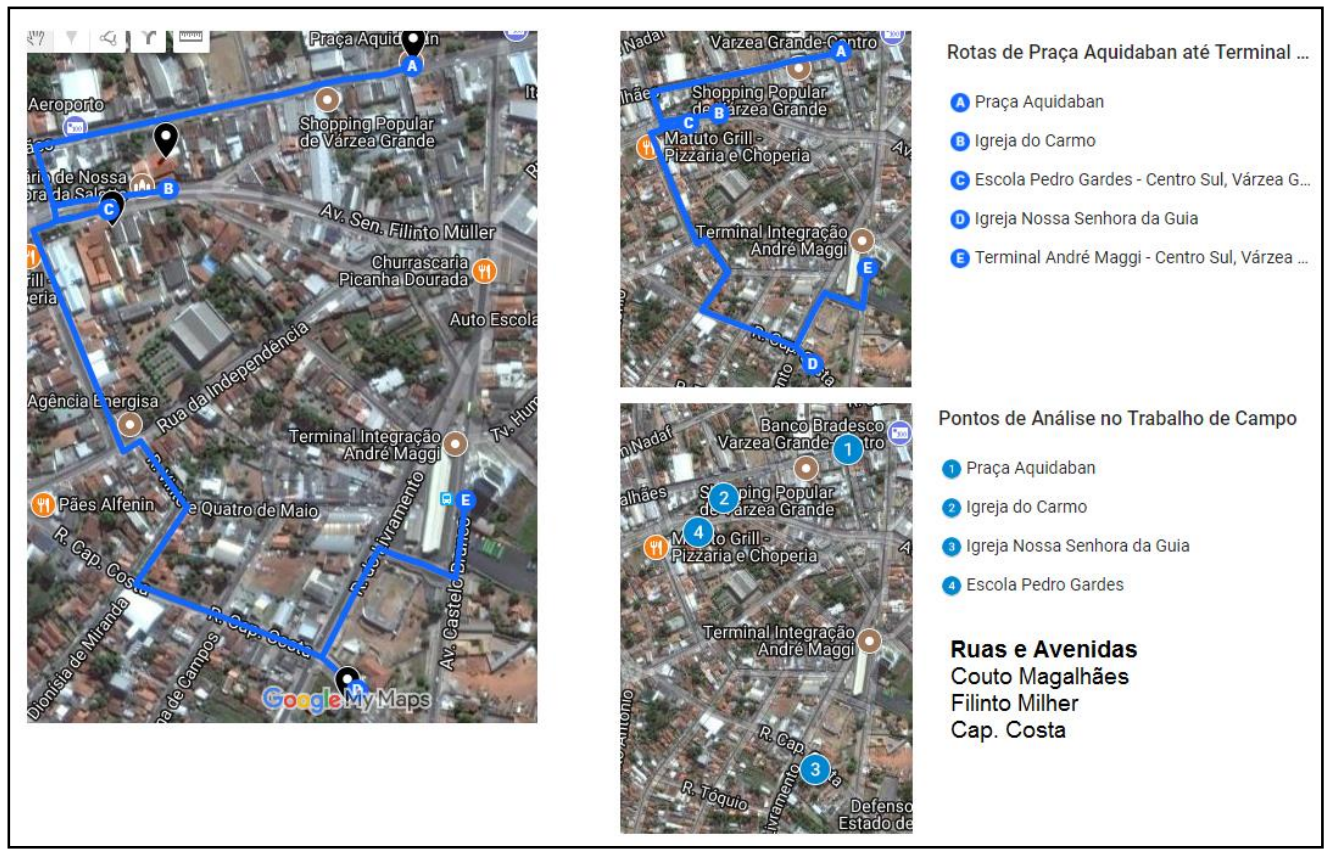

Fonte: Gabriel M. S. Silva (2019).

Ao longo do trabalho de campo os alunos fizeram registros fotográficos com os aparelhos de telefones celulares, buscou-se uma interação com a tecnologia, já que todos os alunos presentes possuíam um smartphone, também existiam câmeras digitais disponíveis aos alunos que não tinham acesso a um smartphone. Propomos aos alunos uma observação da transformação das paisagens na área central da cidade com base nas transformações socioespaciais que aconteceram ao longo da história e, que moldaram a paisagem da área central da cidade. Oliveira (2010, p. 154) instiga que durante a atividade de campo os alunos devem compreender as diferenciações

[...] entre as paisagens observadas nos livros didáticos com as paisagens vivenciadas in loco, estas movidas e vivificadas pela relação dos alunos com as configurações óticas apreciadas sem recortes, vistas justamente com os movimentos das relações sociais seus diferentes tipos de domínios/ uso e seu entrono, a combinação de objetos naturais e artificiais - um instante da relação sociedade-espaço - num verdadeiro conjunto das coisas.

Além das paisagens analisamos as transformações das edificações que se localizam na região central, com destaque para a Igreja de Nossa Senhora da Guia, tombada pelo patrimônio histórico e cultural do município, já que apresenta importante marco no processo de consolidação da cidade de Várzea Grande. Na figura 05 destacamos a apresentação aos alunos que aconteceu no interior da igreja, e demonstrando sua importância na paisagem urbana de Várzea Grande. 
Figura 05: Apresentação do Modelo Arquitetônico da Igreja de Nossa Senhora da Guia

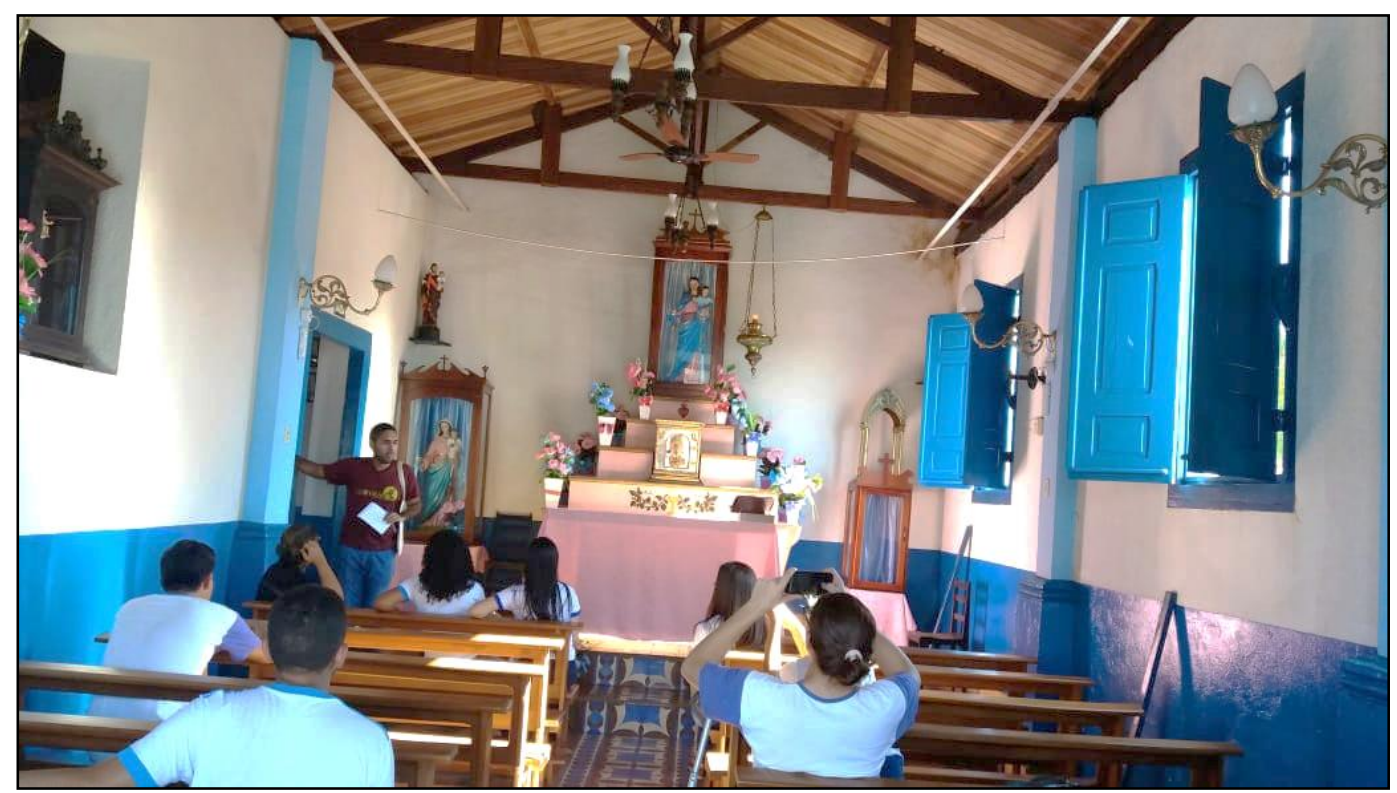

Fonte: A. R. G. C. (2018).

A interação com os diferentes espaços tornou mais enriquecedor o trabalho de campo, como evidência Pontuschka (et al, 2007, p. 180).

Durante o trabalho de campo, educadores e educandos precisam superar o cotidiano que impede o sentir e o criar constrói empecilho para chegar ao conhecimento. Esse é o momento do diálogo: com o espaço, com a história, com as pessoas, com os colegas e seus saberes e com tantos outros elementos enriquecedores de nossa prática e de nossa teoria.

As autoras ainda destacam que devemos sair para uma atividade de campo sem prejulgamentos ou preconceitos, estar disposto a "liberar o olhar", para uma leitura afetiva dos diversos espaços a serem percorridos (PONTUSCHKA et al, 2007, p. 180).

\section{Fotografia}

No item anterior ressaltamos a relevância do trabalho de campo no processo de ensino e aprendizagem de Geografia. Sobre a fotografia, esta se apresentara como técnica que complementou as observações realizada no decorrer do trabalho de campo, desta forma salientamos a importância da observação das paisagens e suas transformações. Silva, et al (2017. p. 1) enfatiza que 
paisagem em um determinado tempo e espaço. O uso da fotografia em sala de aula pode levar esse aluno a despertar o interesse pela Ciência Geográfica.

Concordamos com o autor quando enfatiza a leitura da paisagem relacionada à fotografia, na busca dos ângulos outras leituras de mundo poderão ser realizadas. Adicionalmente Cavalcanti (2016) ressalta que o foco e a atenção dos alunos em sala de aula acontecem quando algo desperta o seu interesse, neste sentido propomos a utilização de smartphone, para fotografarmos alguns pontos ao longo do trabalho de campo.

Como já destacado a escola se localiza próxima aos pontos visitados durante o trabalho de campo, os alunos transitam por estes pontos cotidianamente, assim, a intenção da utilização da técnica de fotografias, foi propor que os alunos olhassem estes espaços de maneira diferente; com olhar cientifico, crítico e criativo, para a compreensão dos conceitos da Geografia e aplicação dos saberes cotidianos.

Ao final da atividade do trabalho de campo, os alunos selecionaram as fotos para impressão (que foi custeada pelos acadêmicos que realizavam o projeto na escola) e compuseram um painel com a síntese da aula de campo no pátio da escola. Com as fotografias antigas apresentadas no momento anterior ao trabalho de campo e com as fotografias que os alunos registraram, na figura 06, é possível visualizar o painel exposto no pátio da escola.

Figura 06: Painel exposto no pátio da escola

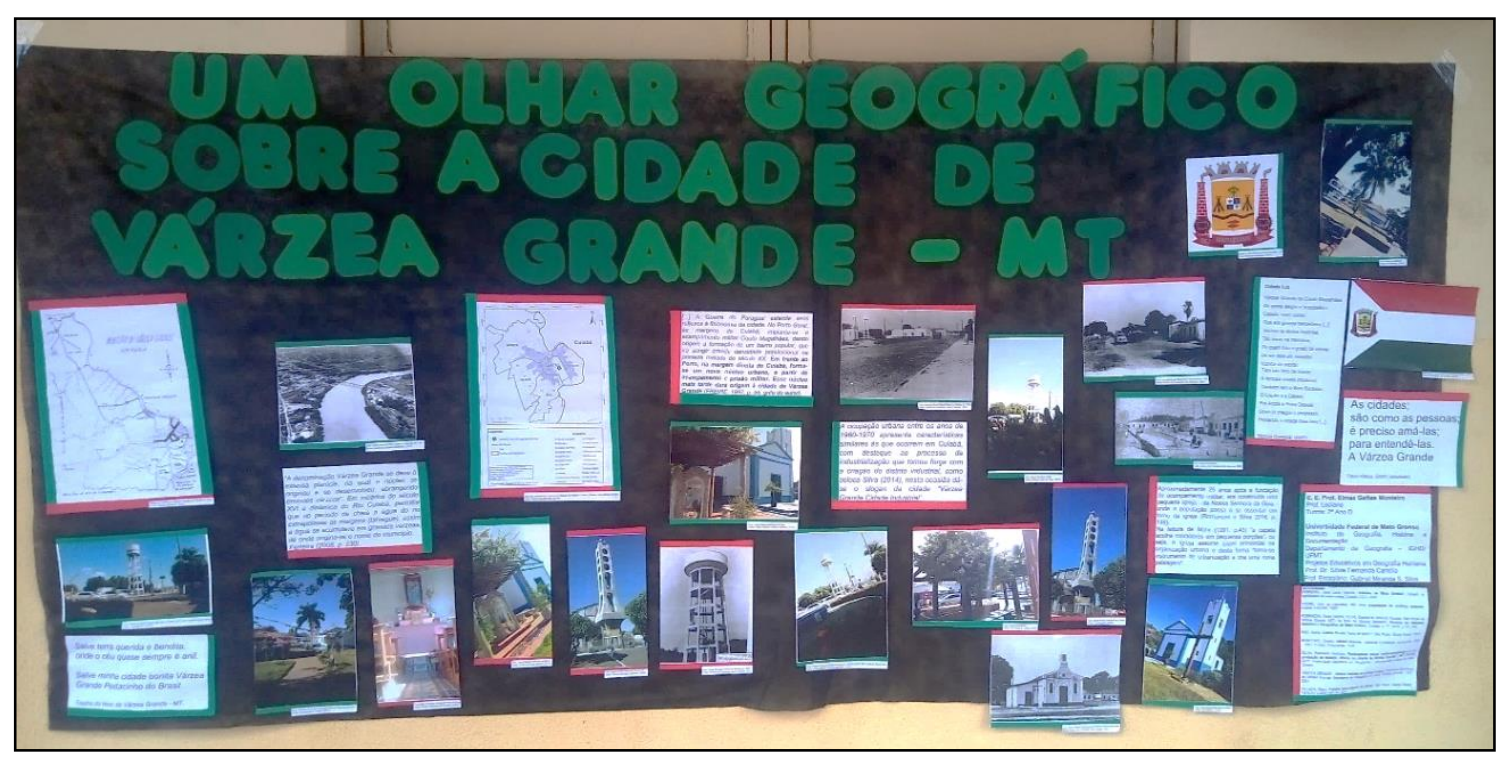

Fonte: Gabriel M. S. Silva (2019). 
Com a elaboração deste painel os alunos que participaram das atividades de campo e fotografia, tiveram a oportunidade de observar as transformações no espaço urbano, de forma mais dinâmica, até porque, puderam visualizar a partir do olhar geográfico dos próprios sujeitos/estudantes, envolvidos nesse projeto e, assim, produziram as suas análises, interpretações, visões e revisões da organização espacial urbana desta área do município. Também teceram comparações sobre a transformações e permanências destes espaços, assim provendo o exercício de despertar o espírito científico, crítico e criativo.

\section{Jogo de tabuleiro}

Com base nas atividades já desenvolvidas, aula expositiva, aula e trabalho de campo e confecção de painel, realizamos uma análise com o propósito de confeccionar um jogo de tabuleiro. A intenção com o jogo de tabuleiro foi motivar a interação dos alunos com os conceitos e conteúdos envolvidos nas atividades, com aplicação para cerca de 35 alunos.

A proposta metodológica para o desenvolvimento do jogo se baseia na leitura de Castellar e Vilhena (2014), onde destacam a importância de jogos e atividades lúdicas, que auxiliam não só no processo de ensino e aprendizagem, mas também nas percepções cognitivas, afetivas, psicomotoras e atitudinais, além de promover a integração das relações sociais adquiridas pelas observações da realidade e dos percursos percorridos no jogo. Ou seja, o jogo, uma atividade lúdica, auxilia a aprender e a pensar sobre o espaço em que se vive.

O jogo de tabuleiro desenvolvido foi intitulado "Nas trilhas de Várzea Grande", já que teve como objetivo uma análise sobre o processo de urbanização da cidade, como demonstra a figura 10. 
Figura 10: Tabuleiro do Jogo

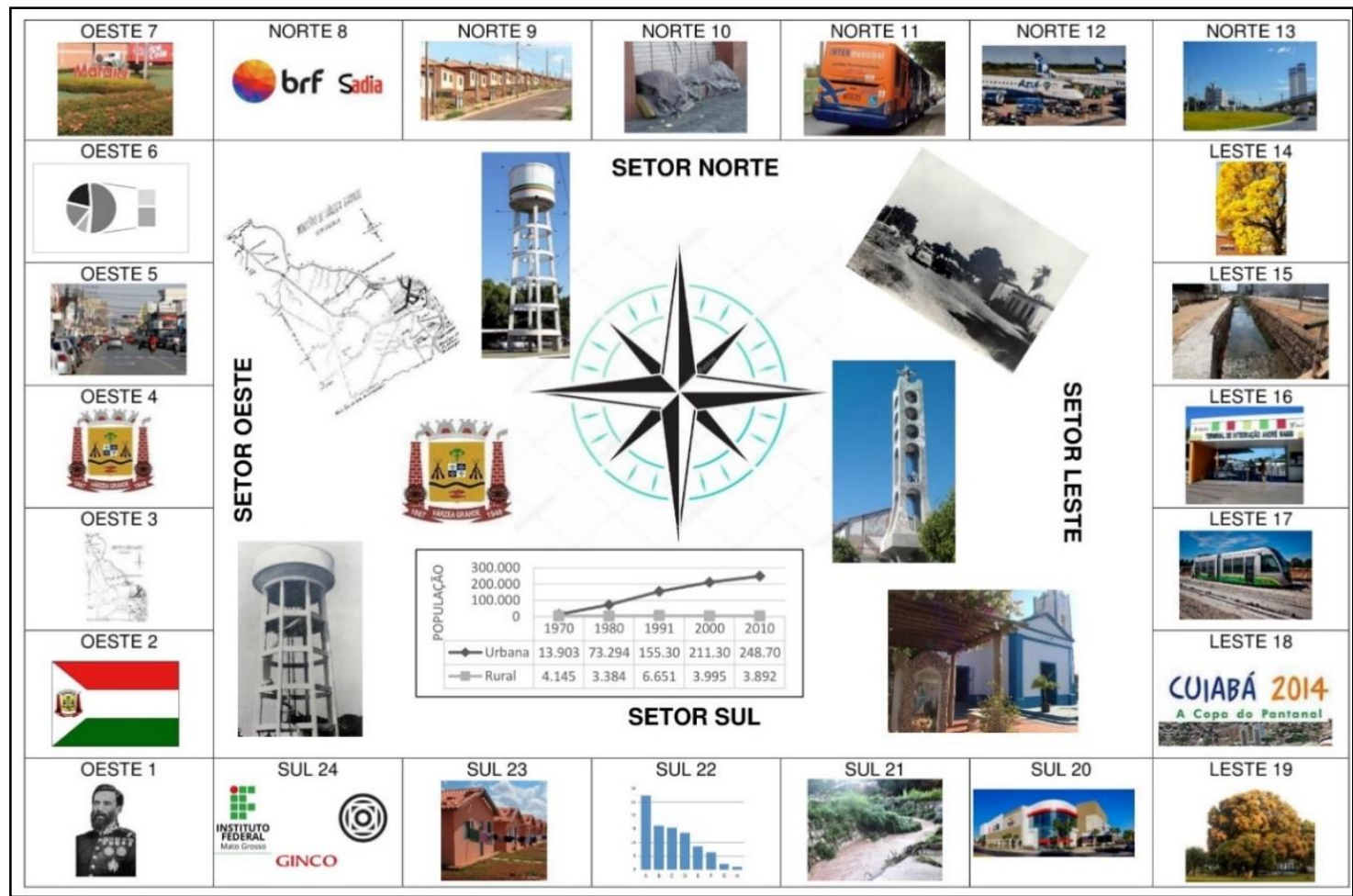

Fonte: Gabriel M. S. Silva (2019).

A proposta do jogo se baseou no Jogo da Vida, um jogo de tabuleiro (vendido em lojas de brinquedos) onde os jogadores perdem e ganham dinheiro (fictício no jogo), já no jogo desenvolvido no projeto a ideia é que os alunos avancem ou retornem as casas (enumeradas e com os pontos cardeais norte, sul, leste e oeste). Ao longo do jogo, os alunos deverão analisar o processo de urbanização da cidade, e perceber fatores que promovam o avanço dos estudantes ou que fiquem estagnados no jogo.

Imprimimos a base do jogo em uma folha do tamanho A3 e colamos em uma base de papelão, o mesmo foi realizado para a produção dos peões que representassem onde os alunos estão no tabuleiro durante o jogo. Também foram impressas as cartas com as mensagens de cada casa enumerada presente no tabuleiro e confeccionados dados onde os alunos jogavam o dado que designava a casa que o aluno iria se posicionar.

A figura 11 demonstra a aplicação do Jogo na sala da escola Elmaz Gattas Monteiro. 
Figura 11: Aplicação do Jogo

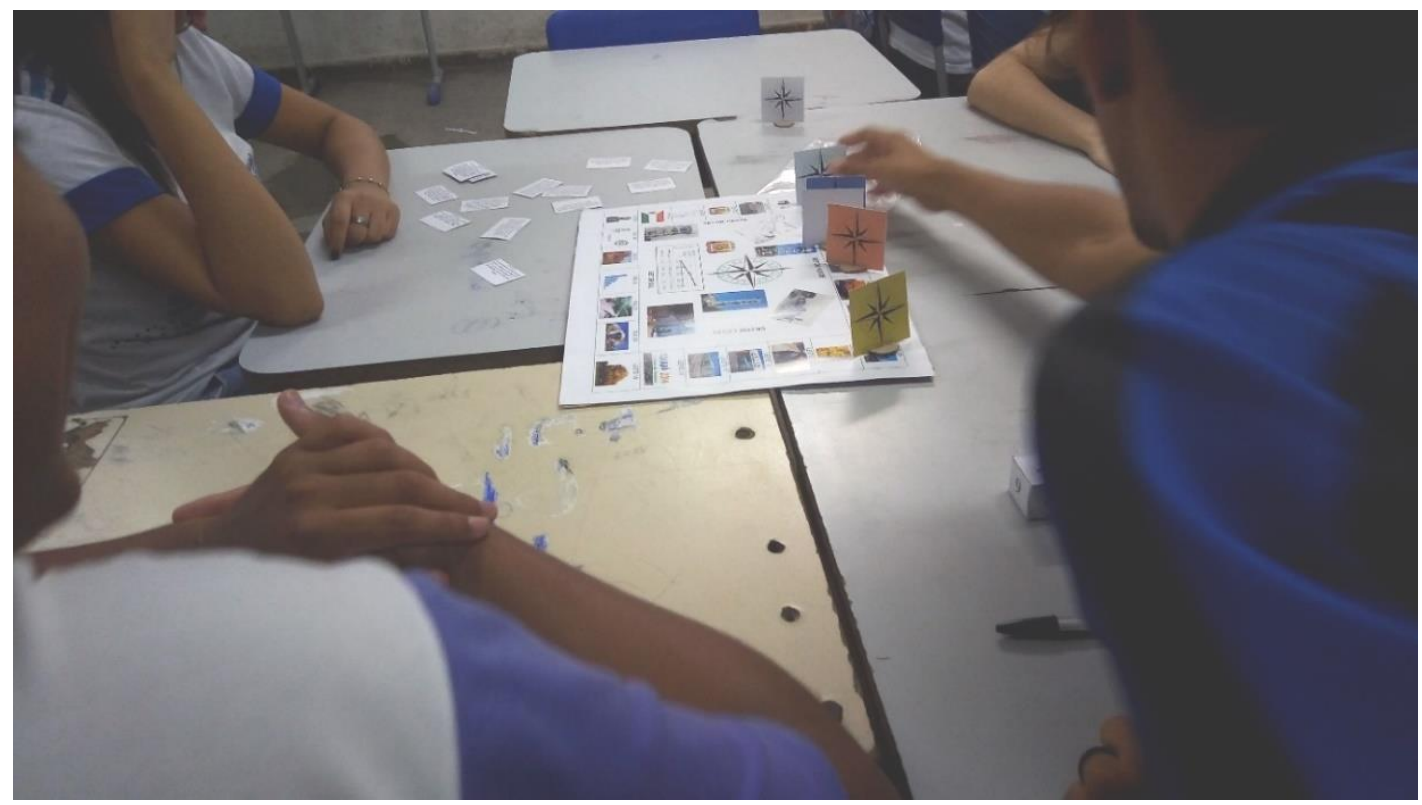

Fonte: Gabriel M. S. Silva (2019).

O jogo sugere apresentar em sala de aula novos questionamentos, procurando aguçar nos alunos um pensamento crítico em forma de uma "brincadeira" dinâmica, onde mesmo que por um instante irão poder refletir sobre o seu cotidiano e sua vida, além de como e para quem este espaço é moldado.

Dessa maneira é que justificamos a importância do jogo para aqueles alunos, proporcionar a transformação de informações em conhecimento, uma vez que os leva ao pensar, por exemplo: o motivo da instalação do Shopping de Várzea Grande Shopping naquele local em frente a um aeroporto internacional, e a que tipo de público aquele espaço busca atender. Isso vai ao encontro no que diz Sacramento (2017, p. 225), que

[...] jogo é um pensamento é o resultado de um exercício reflexivo sobre algo concreto, no qual estão representes regras, condutas, valores, conceitos e identidades. [...] o jogo como atividade de ensino, que é de criar, executar, formas aos quais os estudantes consigam chegar ao resultado final por meio de erros e acertos.

A autora ainda destaca que os jogos didáticos auxiliam a estimular a descrição, a análise, a associação e a criação de situações que proporcionam a compreensão de conceitos e dos conteúdos. Entretanto, questionamentos relevantes como perguntas simples, sobre a distância de sua residência, ou como chegam à escola, evidenciam de forma crítica sobre acontecimentos que ocorrem na cidade. 
Outras situações como os de congestionamentos, alagamentos que acontecem no cotidiano da cidade, evidenciam conteúdos referentes ao planejamento urbano, segregação socioespacial e mobilidade urbana, e, podem ser observados ao longo do jogo. Lembramos aqui o que disse Lana Cavalcanti na apresentação do seu livro "A Geografia escolar e a cidade" quando menciona as cidades como ponto de atenção de diversos profissionais e diz que

São muito relevantes, nesse caso, estudos que buscam compreender o espaço urbano relacionado a modos de vida, pois ele é produzido para que seus habitantes - diferentes grupos, diferentes culturas, diferentes condições sociais - possam praticar a vida em comum, compartilhando arranjos, desejos, necessidades, problemas cotidianos (CAVALCANTI, 2008, p. 7).

Compreende-se que a para a educação escolar, a Geografia Urbana é um conteúdo importante a ser explanado aos estudantes desta idade escolar. Todavia, além de fazer parte do conteúdo programático, os docentes devem trabalhar com essa importante área buscando proporcionar a formação do pensamento crítico dos estudantes e, sobretudo, a cidadania.

Após a aplicação de todas as atividades propostas, debatemos com os alunos a importância de pontos indicados ao longo do jogo, e eles se disseram que se identificam com vários dos assuntos apresentados. Já vivenciavam aqueles "problemas” no seu cotidiano. A atividade (jogo) ganha maior importância no âmbito escolar, já que coloca assuntos recorrentes do cotidiano vivido aliado aos saberes científicos da Geografia e de maneira lúdica, que proporciona maior interação entre os alunos, como também, facilita a apresentação e formação do pensamento crítico a respeito da organização/reorganização socioespacial urbana local para esses estudantes.

\section{CONSIDERAÇÕES FINAIS}

Ao longo de todo o processo de formulação das atividades apresentadas neste artigo, nos propusemos a evidenciar ferramentas e propostas metodológicas para desenvolver de maneira diferenciada o ensino de Geografia. A Escola Elma Gattas Monteiro por se tratar de uma instituição pública, está vulnerável aos problemas que ocorrem na educação pública e, mesmo em parte das instituições particulares, com o ensino pautado em métodos de ensino ultrapassados, sem contextualização e sem atração aos jovens do século XXI. E, isto pode proporcionar desinteresse dos alunos em estudar e compreender a ciência geográfica. 
Enfrentamos algumas dificuldades para a realização da aula de campo, em espaços próximos da escola, o que foi motivo para queixa de alguns pais de alunos que não compreenderam a importância de metodologia diferenciada. Cabe também destacar que de uma turma de 35 alunos, apenas 10 se fizeram presente na aula de campo e cumpriram com as atividades de fotografia para a confecção do painel. Talvez estes problemas acarretem a desmotivação dos profissionais docentes que se encontram em sala de aula, fazendo assim que estes se utilizem dos métodos descontextualizados já mencionados aqui. Porém, mesmo com um número pequeno de alunos levando em consideração a totalidade da turma, a aula de campo, de fato, proporcionou um movimento inovador promovendo um olhar geográfico destes alunos sobre os pontos visitados.

No último processo da pesquisa, a aplicação do jogo, contamos com a participação de mais alunos, já que atividade foi realizada no ambiente escolar e o retorno foi percebido de imediato, quando os alunos estavam jogando e após uma conversa rápida sobre suas percepções em relação a alguns pontos destacados no jogo. Utilizar uma forma lúdica no ensino de Geografia é promover diferentes formas de ensinar e aprender, despertando o interesse dos alunos, que já estão acostumados aos métodos tradicionais.

Nos propomos a demonstrar e propor ferramentas metodológicas para o ensino de Geografia Urbana, nos pautando em propostas clássicas como trabalho de campo e fotografias adaptadas para a educação escolar e, inovadoras como um jogo desenvolvido com o propósito de pensar a cidade de Várzea Grande. Com as demonstrações dos discentes acreditamos que alcançamos o objetivo.

Salientamos que a pesquisa não se encerra com este trabalho e demanda de mais pesquisas na área, fazendo assim que os profissionais docentes sempre se encontrem atualizados quanto aos métodos de ensinar e aprender Geografia.

\section{REFERÊNCIAS}

BRASIL. Instituto Brasileiro de Geografia e Estatísticas - IBGE. IBGE CIDADES. Disponível em <http://cidades.ibge.gov.br/xtras/perfil.php?lang=\&codmun=510840\&search=mato-grosso|varzeagrande> Acesso em 26. Dez. 2018.

CASTEllAR, S; VILHENA, J. (Orgs.). Ensino de geografia. São Paulo: CengageLearing, 2010.

CANTOIA, S. F. Trabalho de campo e educação ambiental: o caso do córrego do gambá - CuiabáMT. Caderno Prudentino de Geografia, Presidente Prudente, n.36, Volume Especial, p. 268-282, 2014. 
CAVALCANTI, L. S. O olhar geográfico em formação: jovens estudantes de geografia e desafios urbanos contemporâneos. In: PAULA, F. M. A; CAVALCANTE, L. S; PIRES, L. M. (Orgs.). Os jovens e suas espacialidades. Goiânia: Editora Espaço Acadêmico, 2016. p. 121-142.

. A Geografia escolar e a cidade. Ensaios sobre o ensino de Geografia para a vida urbana. São Paulo: Papirus, 2008.

Geografia, escola e construção de conhecimentos. Campinas, SP: Papirus, 1998.

FERREIRA, J. C. V. Cidades de Mato Grosso: Origem e significados de seus nomes. Cuiabá: J.C.V. 2008.

FERREIRA, E. S. O estatuto da cidade como instrumento de planejamento urbano nos municípios de Cuiabá e Várzea Grande - MT. Cuiabá, 2014. Dissertação (Mestrado em Geografia) - Universidade Federal de Mato Grosso.

FREIRE, J. L. Por uma poética popular da arquitetura. Cuiabá: EdUFMT, 1997.

MAX, M. Cidade Brasil terra de quem?.São Paulo: Edusp/ Nobel, 1991.

MONTEIRO, U. Várzea Grande: passado e presente, confrontos. 1867 - 1987. Cuiabá: Policromos, 1988.

OLIVEIRA, C. D. M. Sentidos da geografia escolar. 2. ed. Fortaleza: Edições UFC, 2010.

PONTUSCHKA, N. N; PAGANELLI, T. I; CACETE, N. H. Para ensinar e aprender geografia. São Paulo: Cortez, 2007.

ROMANCINI, S. R; SILVA, G. M. S. Nas trilhas de Várzea Grande (MT) na obra de Ubaldo Monteiro. Revista do Instituto Histórico e Geográfico de Mato Grosso, Cuiabá, n. 77, 2016, p 131-148.

SACRAMENTO, A. C. R. A produção de jogos na formação docente: material didático ensino de geografia. In: PORTUGUAL, J. F. (Org.). Educação Geográfica: temas contemporâneos. Salvador: EDUFBA, 2017. p. 221-233.

SILVA, I. F. F.; SANTOS, F. K. S; SILVA, L. L; CANÊJO, V. P. Fotografia como recurso mediático no ensino de geografia: a paisagem urbana em múltiplos olhares e convergências. In: Encontro Nacional de Prática de Ensino de Geografia. 13. Anais do XIII Encontro de Prática Docente de Geografia. Belo Horizonte, $2017 . \quad$ Disponível em <https://www.ufpe.br/documents/1147022/1148797/Artigo+ENPEG+2017+\%5BITALLO\%5D.pdf/ 5335d3b9-aff4-4196-bc0d-e9ff3c012e29> Acesso em 16 Dez. 2018.

SILVA, R. B. Participação social institucionalizada e a re-produção do espaço urbano na cidade de Várzea Grande - MT. Cuiabá, 2015. Dissertação (Mestrado em Geografia) - Universidade Federal de Mato Grosso. 
THEVES, D. W; KAERCHER, N. A. Saída de campo e geografia escolar. In: PORTUGUAL, Jussara Fraga. (Org.). Educação Geográfica: temas contemporâneos. Salvador: EDUFBA, 2017. p. 273288.

KAERCHER, N. A. Geografizando o jornal e outros cotidianos: práticas em geografia além do livro didático. In: CASTROGIOVANNI, A. C; CALlAI, H. C; KAERCHER, N. A. (Orgs.) Ensino de geografia: práticas e textualizações no cotidiano. Porto Alegre: Mediação, 2006. p. 135-170.

VÁRZEA GRANDE. Câmara Municipal de Várzea Grande. Lei Complementar N. $^{0} .727$ de Fevereiro de 2012 de Zoneamento de Uso e Uso e Ocupação do Solo Urbano. Legislação Municipal. Várzea Grande: 2012.

Câmara Municipal de Várzea Grande. Lei Complementar N. ${ }^{\circ} 3.112$ de Dezembro de 2007 Institui o Plano Diretor do Município de Várzea Grande e dá outras providências. Legislação Municipal. Várzea Grande: 2007. 